8 - ORIGINAL ARTICLE

EXPERIMENTAL UROLOGY

\title{
Measurement of testicular volume in Wistar rats using a caliper and ultrasonography in experimental surgery ${ }^{1}$
}

\author{
Salomão Brêtas', Edson Samesima Tatsuo ${ }^{I I}$, Monica Odete Oliveira Brêtas ${ }^{\text {III }}$, Caroline Oliveira Brêtas ${ }^{\text {IV }}$ \\ DOI: http://dx.doi.org/10.1590/S0102-865020160070000008
}

${ }^{\mathrm{I}}$ Fellow PhD degree, Postgraduate Program in Sciences Applied to Surgery and Ophthalmology, School of Medicine, Universidade Federal de Minas Gerais (UFMG), Brazil. Concept, design, and intellectual content of the study; manuscript preparation; technical procedures.

IIPhD, Full Professor, Department of Surgery, School of Medicine, UFMG, Belo Horizonte-MG, Brazil. Concept, design, and intellectual content of the study; manuscript preparation; critical revision.

IIIMD, Fellow, Audit and Regulation Mechanisms in Health, Fundação Unimed, Universidade Gama Filho (UGF), Rio de Janeiro-RJ, Brazil. Acquisition and interpretation of data.

${ }^{\mathrm{IV}}$ Graduate student, Medical Sciences, Escola Superior de Ciências da Santa Casa de Misericórdia de Vitória (EMESCAM), Vitória-ES, Brazil. Acquisition and interpretation of data, technical procedures.

\section{ABSTRACT}

PURPOSE: To compare the measurement of the testicular volume of Wistar rats using a caliper and ultrasonography.

METHODS: Forty Wistar rats were randomly assigned into four groups. A tensile force of $1.6 \mathrm{Newton}(\mathrm{N})$ and $1.0 \mathrm{~N}$ was applied to the right spermatic cord in group I and group II, respectively. Group III was the sham group, and group IV served as a control. The initial and final testicular volumes were measured using a caliper and ultrasonography and compared. A significance level of 5\% was used.

RESULTS: The Kappa coefficient was equal to $0.292(\mathrm{p}=0.006)$. The Pearson correlation coefficient obtained for the percent reduction in the right testicular volume using ultrasonography and a caliper was equal to $0.696(\mathrm{p}<0.001)$.

CONCLUSION: There was reasonable agreement and a significant positive correlation between the percent reduction in the right testicular volume using ultrasonography and a caliper.

Key words: Ultrasonography. Testis. Orchiopexy. Traction. Rats. 


\section{Introduction}

The measurement of testicular volume is important in the evaluation of patients with diseases that affect the growth and development of the testes. Therefore, the measurement of testicular volume is useful for assessing pubertal development and the damage caused in this organ by trauma, orchitis, epididymitis, vasectomy, and inguinal hernia. In addition, it can serve as a parameter for the treatment of diseases that compromise fertility. Testicular volume reflects spermatogenesis because approximately $70 \%$ to $80 \%$ of the testicular mass consists of seminiferous tubules, and these structures are correlated with the count, motility, morphology, and daily production of sperm cells ${ }^{1}$.

The aim of the present study was to compare the testicular volume of Wistar rats measured with a caliper and with ultrasonography.

\section{Methods}

The present study was approved by the Ethics Committee on Animal Use, Universidade Federal de Minas Gerais, under protocol $n^{\circ} 86 / 2012$. The animals were handled according to the procedures for the use of experimental animals recommended by the Brazilian Society of Science in Laboratory Animals/Brazilian School of Animal Experimentation.

Forty adult Wistar rats, with an average age of 128.8 \pm 3.5 days, were used. The animals were anesthetized via an intramuscular injection of $10 \%$ ketamine hydrochloride at $60 \mathrm{mg} /$ $\mathrm{kg}$ and $2 \%$ xylazine at $10 \mathrm{mg} / \mathrm{kg}$.

The experimental plan included the performance of two surgeries. Preoperatively, a veterinarian made the ultrasound examination of the right and left testes and calculated the testicular volume of all rats, blindly, without prior knowledge of the animal groups evaluated.

The testicular volume calculated preoperatively in the first surgery was designated the "initial testicular volume", and the testicular volume calculated preoperatively in the second surgery was designated the "final testicular volume".

In the first surgery, surgical access was achieved via a longitudinal paramedian supratesticular incision on the right side. The right side of the scrotum was standardized as the side of choice for the procedure. The left side of the scrotum was not manipulated. The right spermatic cord, testis, and epididymis were exposed through this incision. A window was created in the right spermatic cord between the vas deferens and the testicular vessels, near the epididymis. A Kenzaki Release $11^{\circledR}$ carbon steel fishing hook with a barbless shank and a barbless point was introduced into this window. This type of hook is used to avoid trauma to the components of the spermatic cord. A 1-m-long thread of 2.0 monofilament nylon was used to tie the hook to the dynamometer (Figure 1), first passing through a simple pulley (EQOO8.56, $\left.\mathrm{CIDEPE}^{\circledR}\right)$.

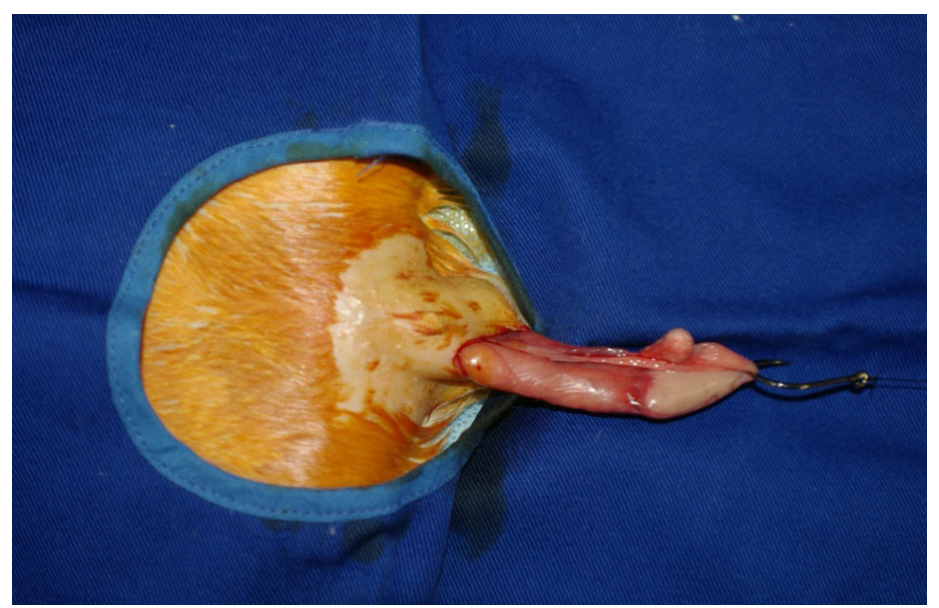

FIGURE 1 - The hook was introduced into the window created in the right spermatic cord and is tied to surgical thread in order to help with the traction process

The dynamometer and pulley were fixed on a $46.5 \times 62.0$ cm magnetic board (model TBF-106 MINIPA $^{\circledR}$ ) and mounted on a $97 \times 85 \times 34 \mathrm{~cm}$ multipurpose demonstration structure (model TBF-100 MINIPA $^{\circledR}$ ) containing a $93 \times 32 \mathrm{~cm}$ shelf (model TBF101 MINIPA $\left.^{\circledR}\right)$. A continuous traction force in the horizontal direction was applied to the right spermatic cord in the distal direction for 5 minutes (Figure 2). The gubernaculum was not sectioned in the first surgery. Subsequently, the right spermatic cord together with the ipsilateral testis and epididymis was repositioned in the scrotum, and the surgical wound was closed using a 4.0 nylon monofilament; in addition, the muscular wall and the peritoneum were closed at a single plane using a simple continuous running suture, and the skin was closed with separate stitches. The left spermatic cord was not manipulated in the first surgery and consequently was not subjected to tensile forces.

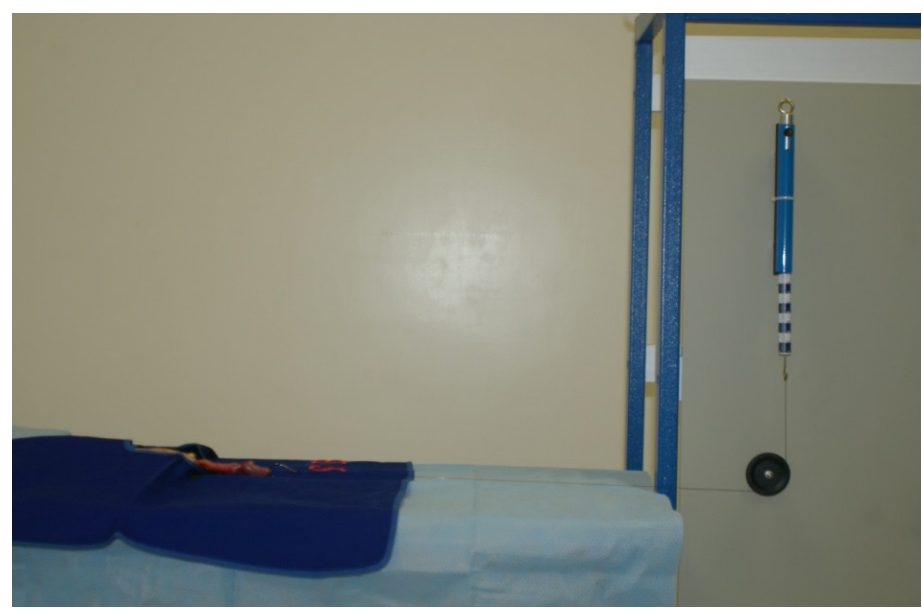

FIGURE 2 - Preoperative traction of the right spermatic cord. The arrow indicates the direction of the stretching force. 
The study animals were randomly allocated by drawing lots into 4 groups of 10 animals. In group I $(n=10)$, a perioperative tensile strength of 1.6 Newton $(\mathrm{N})$ was applied to the right spermatic cord. In group II $(\mathrm{n}=10)$, a tensile force of $1.0 \mathrm{~N}$ was applied. The value of $1.0 \mathrm{~N}$ corresponds to 0.10197 kilogramforce $(\mathrm{kgf})$. Group III $(\mathrm{n}=10)$ served as the sham group and was subjected to the procedures above, but no traction force was applied in this group. Group IV $(\mathrm{n}=10)$ was used as a control and did not undergo the first surgery; consequently, the right spermatic cord was not pulled in this group.

Intraoperatively, in the first surgery, before the tensile force was applied to the right spermatic cord, the members of the surgical team measured the dimensions of the right testis of the animals from groups I, II, and III with a digital caliper (model IP54 100.179G DIGIMESS ${ }^{\circledR} 150 \mathrm{~mm}$ ), with a reading accuracy of $0.01 \mathrm{~mm}$, to calculate the initial testicular volume. In the animals from group IV, the initial volume was not calculated because the animals of this control group were not subjected to the first surgery.

On the 28th day after the first surgery, all animals were subjected to the second surgery. Intraoperatively, in the second surgery, the members of the surgical team measured the dimensions of the right and left testis of the animals from groups I, II, III, and IV with a digital caliper to calculate the final testicular volume. After that, all animals were euthanized.

The testicular volume was calculated using two distinct strategies:

a) By ultrasonography using a Logic portable ultrasound apparatus $\left(\mathrm{GE}^{\circledR}\right)$ with an $8 \mathrm{C}$ micro-convex transducer at a frequency of $6 \mathrm{MHz}$ to $10 \mathrm{MHz}$; this device automatically measures testicular size and volume using the formula $0.523 \mathrm{x}$ length $\mathrm{x}$ width $\mathrm{x}$ thickness. b) Using the testicular dimensions measured with a caliper intraoperatively and the formula for the calculation of a solid ellipsoid triaxial body, as described by $\mathrm{Nistal}^{2}$ and Love $^{3}$ :

$4 \pi \mathrm{abc} / 3$

This formula was used considering a $\pi$ equal to 3.14 and: $a=$ half the height

$\mathrm{b}=$ half the width

$\mathrm{c}=$ half the length

A significance level of $5 \%$ was used. The Kappa coefficient ${ }^{4}$ and Pearson coefficient were calculated to evaluate the concordance and correlation between the results obtained using the caliper and ultrasonography, respectively.

\section{Results}

One animal from group IV was excluded because of granulomatous orchitis in the right testis diagnosed during the histopathological examination. Therefore, 39 rats were considered in this study. Group IV comprised 9 rats.

\section{Comparison between the right and left testicular volume measured using a caliper and ultrasonog- raphy}

The comparison of the left and right testicular volumes measured using a caliper and ultrasonography is shown in Table 1. A significant difference $(\mathrm{p} \leq 0.05)$ was found in the initial right testicular volume, in the variation of the right testicular volume (final - initial), and in the final left testicular volume. Therefore, the methods used for measuring the volumes differed.

TABLE 1 - Comparison between the left and right testicular volumes measured with a caliper and ultrasonography.

\begin{tabular}{|c|c|c|c|c|c|c|c|c|c|}
\hline \multirow{3}{*}{ Characteristics } & \multicolumn{8}{|c|}{ Testicular volume $\left(\mathrm{cm}^{3}\right)$} & \multirow{3}{*}{ p-value } \\
\hline & \multicolumn{4}{|c|}{ Caliper } & \multicolumn{4}{|c|}{ Ultrasonography } & \\
\hline & $\mathrm{n}$ & Mean & $\mathrm{SD}$ & Median & $\mathrm{n}$ & Mean & $\mathrm{SD}$ & Median & \\
\hline Initial testicular volume & 30 & 1.2 & 0.2 & 1.2 & 30 & 1.5 & 0.3 & 1.6 & $<0.001^{2}$ \\
\hline Final testicular volume & 39 & 1.1 & 0.4 & 1.0 & 39 & 1.1 & 0.4 & 1.1 & $0.611^{2}$ \\
\hline \multicolumn{10}{|l|}{ Left side } \\
\hline Final testicular volume & 39 & 1.4 & 0.2 & 1.4 & 39 & 1.6 & 0.3 & 1.6 & $0.002^{2}$ \\
\hline
\end{tabular}

$\mathrm{n}=$ number of animals in each group; $\mathrm{SD}=$ Standard Deviation

${ }^{1}$ Wilcoxon test; ${ }^{2}$ Paired t-test.

With regard to the initial right testicular volume, there was a difference in the values measured using the caliper and ultrasonography, and the testicular volume measured with ultrasonography was greater than the volume measured with a caliper.

With regard to the variation of the right testicular volume in relation to the initial volume [(final-initial)/initial] x 100, there was a difference in the values when measured using a caliper as 
opposed to ultrasonography. The variation of the testicular volume measured by ultrasonography was higher than the variation obtained using a caliper, indicating that the difference between the initial and final measurements was higher with ultrasonography. The variation of the testicular volume in relation to the initial volume using ultrasonography was $11.4 \%[-36.9-(-25.5)]$, which was higher than the variation obtained using a caliper. This variation ranged from $4.0 \%$ to $18.7 \%$ (95\% CI: 4.0-18.7).

With regard to the right testicular volume, there was a difference in the values measured using a caliper as opposed to ultrasonography, and the testicular volume measured via ultrasonography was greater than that measured using a caliper.

Higher values for the initial right testicular volume and final left testicular volume were detected via ultrasonography. Greater variation of the right testicular volume in relation to the initial volume using ultrasonography was also observed (Figures 3 and 4).

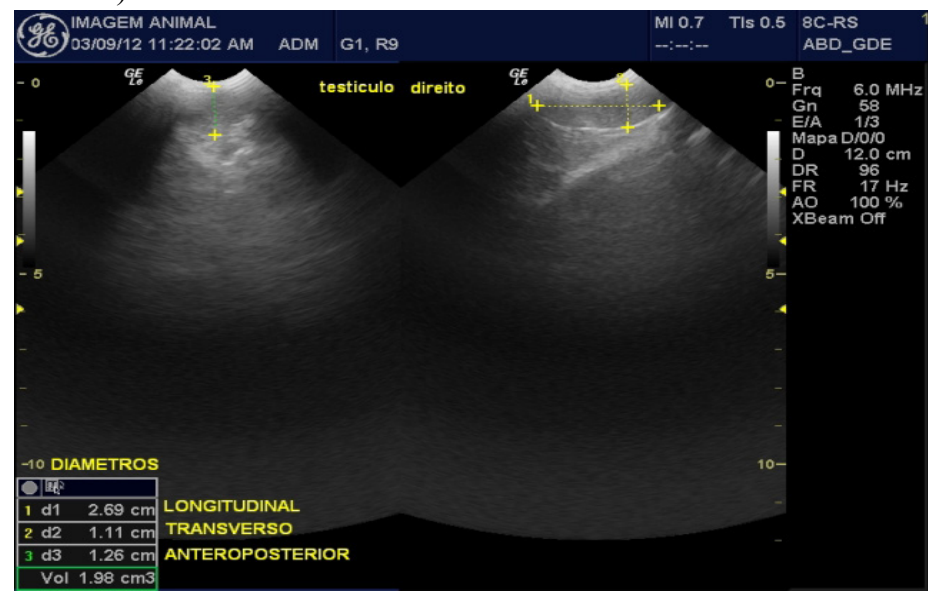

FIGURE 3 - Ultrasonography of the right testis of rat 9 Group I made preoperatively the first operation. The initial testicular volume right was $1.98 \mathrm{~cm}^{3}$

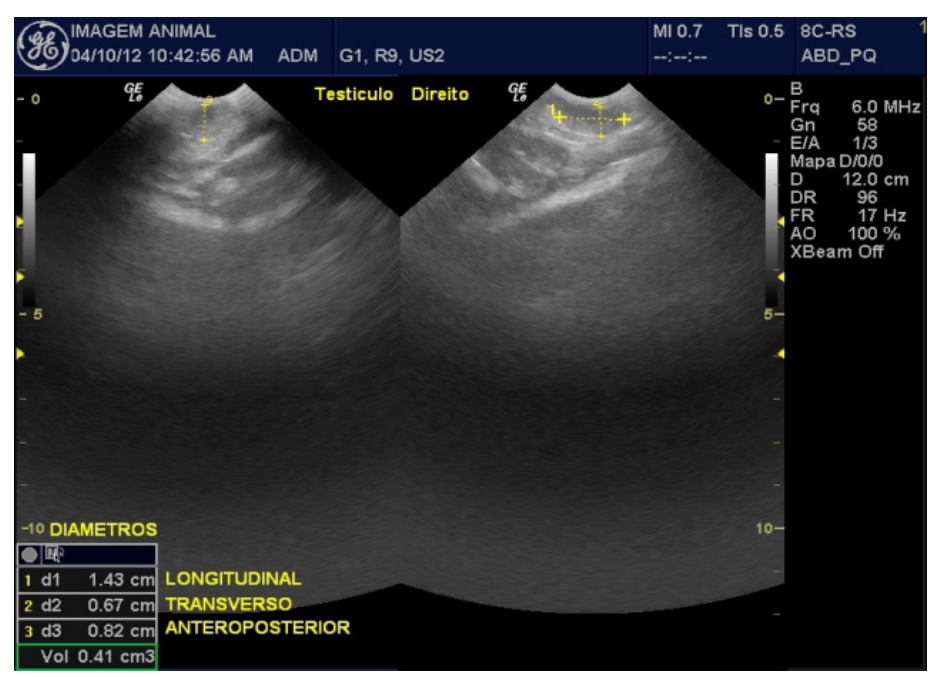

FIGURE 4 - Ultrasonography of the right testis of rat 9 Group I made previous to the second operation. The final testicular volume right was $0.41 \mathrm{~cm}^{3}$.

\section{Reduction in testicular volumes}

The decrease in the left testicular volume by ultrasound and in the right testicular volume by both ultrasound and caliper was calculated as [(final-initial)/initial] $x 100$, resulting in a reduction (in percent) in testicular volume. It is of note that the cases described as "without reductions" were those with a positive percentage for testicular volume. The cases with a reduction of less than $10 \%$ presented values between -9.9 and -0.01 .

Table 2 presents the data grouped by the reduction in testicular volume in relation to the initial volume according to the study group (columns), evaluation method (ultrasonography or caliper) in the highlighted lines, and percent reduction in the highlighted lines.

TABLE 2 - Reduction in testicular volume.

\begin{tabular}{|c|c|c|c|c|}
\hline $\begin{array}{l}\text { Characteris- } \\
\text { tics }\end{array}$ & $\begin{array}{l}\text { Group } \\
\text { I }\end{array}$ & $\begin{array}{l}\text { Group } \\
\text { II }\end{array}$ & $\begin{array}{l}\text { Group } \\
\text { III }\end{array}$ & $\begin{array}{l}\text { Group Total p-value } \\
\text { IV }\end{array}$ \\
\hline
\end{tabular}

Variation of the right testicular volume via ultrasonography $(\%)$

$0.047^{1}$

$\begin{array}{clllll}\text { No reduction } & 0 & 1 & 1 & 3 & 5 \\ <10 & 0 & 0 & 0 & 2 & 2 \\ 10 \text { to } 29.9 & 3 & 7 & 3 & 3 & 16 \\ 30 \text { to } 50 & 4 & 2 & 2 & 1 & 9 \\ >50 & 3 & 0 & 4 & 0 & 7\end{array}$

Variation of the right testicular volume via caliper $(\%) \quad 0.001^{1}$

$\begin{array}{cccccc}\text { No reduction } & 0 & 0 & 4 & \mathrm{X} & 4 \\ <10 & 1 & 0 & 1 & \mathrm{X} & 2 \\ 10 \text { to } 29.9 & 5 & 8 & 0 & \mathrm{X} & 13 \\ 30 \text { to } 50 & 1 & 2 & 3 & \mathrm{X} & 6 \\ >50 & 3 & 0 & 2 & \mathrm{X} & 5\end{array}$

Variation of the left testicular volume via ultrasonography $(\%)$

$\begin{array}{cccccc}\text { No reduction } & 2 & 1 & 2 & 2 & 7 \\ <10 & 1 & 2 & 5 & 2 & 10 \\ 10 \text { to } 29.9 & 4 & 6 & 3 & 5 & 18 \\ 30 \text { to } 50 & 3 & 1 & 0 & 0 & 4\end{array}$

${ }^{1}$ Fisher's exact test.

For the variation of the right testicular volume in relation to the initial volume via ultrasonography, the line labeled "without reductions" indicates how many animals not presented reduced testicular volume. The testicular volume of one animal from group II, one animal from group III, and three animals from group IV did not decrease. 
In another subgroup, the animals were identified by the variation of the right testicular volume in relation to the initial volume assessed using a caliper. The column from group IV is all marked with $\mathrm{X}$ because the initial testicular volume of the animals in this group was not measured using a caliper and, therefore, was not included in this analysis. In the line designated "without reduction", none of the animals from groups I and II presented this classification, and four animals from group III presented this classification.

There was a significant difference in the reduction of the testicular volume assessed via ultrasonography and caliper between the groups ( $p=0.047$ and $p=0.001$, respectively). However, this association could not be determined and quantified owing to the high number of null cases. Visually, we observed more cases with less reduction in the variation of the right testicular volume in group IV via ultrasonography. More cases without reductions in the right testicular volume were observed using a caliper in group
III compared with the other groups.

No significant differences were found in the left testicular volume measured via ultrasonography $(\mathrm{p}=0.427)$.

Table 3 shows the concordance in the percent reduction in the right testicular volume compared with the initial volume in 30 animals from groups I, II, and III. Notably, there were no cases with reductions of less than $10 \%$ with ultrasonography. Therefore, to perform the calculations, the categories "without reductions" and "reductions of $<10 \%$ " were grouped.

In the first row of the table, identified as "no reduction", of the two animals (full line) designated as "without reductions" using ultrasonography (identification of the first column), one was classified using a caliper as without reduction or with a reduction of less than $10 \%$ (second column), and another was classified as having a reduction between $10.0 \%$ and $29.9 \%$. The Kappa coefficient was equal to $0.292(\mathrm{p}=0.006)$.

TABLE 3 - Percent reduction in right testicular volume measured via ultrasonography and caliper in rats from groups I, II, and III.

\begin{tabular}{|c|c|c|c|c|c|c|}
\hline \multirow[b]{2}{*}{ Characteristics } & \multicolumn{4}{|c|}{ Decrease in the volume measured with a caliper $(\%)$} & \multirow[t]{2}{*}{ Total } & \multirow[t]{2}{*}{ p-value } \\
\hline & $\begin{array}{c}\text { Without reduction or } \\
\text { with a reduction of }<10\end{array}$ & 10 to 29.9 & 30 to 50 & $>50$ & & \\
\hline \multicolumn{6}{|c|}{ Reduction in the measurement via ultrasonography (\%) } & 0.006 \\
\hline $\begin{array}{l}\text { Without reduction or with a } \\
\text { reduction of }<10\end{array}$ & 1 & 1 & 0 & 0 & 2 & \\
\hline 10 to 29.9 & 4 & 8 & 1 & 0 & 13 & \\
\hline 30 to 50 & 1 & 4 & 2 & 1 & 8 & \\
\hline$>50$ & 0 & 0 & 3 & 4 & 7 & \\
\hline
\end{tabular}

Kappa $=0.292$ (95\% CI: 0.082 to 0.503$)$.

The Pearson correlation coefficient obtained between the percent reduction in the right testicular volume measured via ultrasonography and caliper was equal to $0.696(\mathrm{p}<0.001)$ (Table 4).

TABLE 4 - Correlation between a reduction in the right testicular volume measured via ultrasonography and a caliper.

\begin{tabular}{lcc}
\hline Characteristic & Coefficient & p-value \\
\hline Reduction in \% in both examinations & 0.696 & $<\mathbf{0 . 0 0 1}^{\mathbf{1}}$ \\
\hline${ }^{1}$ Pearson correlation. & &
\end{tabular}

\section{Discussion}

Several instruments can be used to measure testicular size and volume, including an orchidometer, a caliper, and ultrasound. The main factors that may influence the accuracy of these measurements are the inclusion of part or all of the epididymis, variability in the thickness and elasticity of the scrotal skin, compression of the scrotal contents, and experience of the examiner ${ }^{1}$.

Variation in the measurements of testicular volume may occur because of many formulas available. It is convenient to use the three dimensions of this organ to calculate the volume $e^{1,5,6}$.

There is no consensus on which is the best formula for the calculation of testicular volume $e^{6,7}$. Testicular volume tends to be overestimated by the formula published by Lambert and underestimated by the prolate ellipsoid and Hansen formulas ${ }^{6,8,9}$.

The use of a caliper and orchidometer to measure testicular volume via the scrotum is incorrect because this measurement includes the skin and subcutaneous tissue and may also include the epididymis, thereby overestimating testicular volume $e^{1,6,10-12}$. 
Accordingly, the measurement of testicular volume using a caliper via the scrotum may overestimate the testicular volume by $69 \pm$ $27 \%{ }^{1}$. Therefore, the use of such instruments for measuring the testis via the scrotum can only be justified in clinical practice because of their low cost and when the absolute measurement of the testicular volume is not necessary ${ }^{11-13}$.

However, the use of a caliper is valid for measuring the testicular dimensions intraoperatively ${ }^{14}$. In addition, the use of this device requires great sensitivity by the examiner. For this purpose, the testes need to be slightly suspended because, even resting, the organ on the operating table can distort its shape and cause variations in the mensurements ${ }^{1}$. Stegani et al. ${ }^{15}$ measured the testicular volume in rats using a caliper and the prolate ellipsoid formula.

Considering that the testes have a triaxial ellipsoid shape ${ }^{2}$, the use of a mathematical formula is justified for calculating the volume of a solid triaxial ellipsoid body. Therefore, this study introduced this formula to calculate the testicular volume of Wistar rats using a caliper. This formula is present in the records of the National Institute of Standards and Technology of the United States Department of Commerce and has been used to calculate the testicular volume of horses and humans $s^{2,3,16}$. Montero et al. ${ }^{17}$ also used a digital caliper and a formula based on the testis ellipsoid shape to measure testicular volume in Ansell's mole-rats (Fukomys anselli). However, this formula was different from that used in this study.

Ultrasound examination of the testicle was introduced in $1970^{12}$ and is recognized as the most accurate method for measuring testicular volume in situ ${ }^{1,6}$. It is a noninvasive method that allows for the diagnosis of a wide range of testicular diseases ${ }^{10,17-19}$. Gougoudi et al. ${ }^{20}$ show microlithiasis on testicular ultrasound examination of Wistar rats underwent Fowler-Stephens procedure. The most commonly used formula for calculating testicular volume is the prolate ellipsoid. Ultrasound devices, particularly GE Logiq machines, adopt this formula for calculating testicular volume.

For the measurements of the testicular dimensions, it is necessary to acknowledge that the reliability of the measurements indicates the consistency of an instrument or an examiner under the same assessment conditions. The intra-rater reliability indicates the consistency of the measurements performed by a single observer under the same assessment conditions at two different times. A high intra-rater reliability minimizes the possibility of variations in the calculations. The inter-rater reliability indicates the consistency of the measurements made by different examiners. An error rate of approximately $16 \%$ was found in the measurements of testicular size by multiple observers using a Prader orchidometer ${ }^{21}$.
Ceylan et al. ${ }^{22}$ studied the temporary stretch of spermatic cord of Wistar rats using a traction mechanism similar to this study and assessed the damage in the testis and vas deferens, but not measured testicular volume. Choi et al. ${ }^{23}$ evaluated the effects of compression and stretching of the spermatic cord of SpragueDawley rats using a vascular sling, but did not measure the traction force.

In the present study, there was reasonable agreement and a significant positive correlation in the percent reduction in the right testicular volume measured via ultrasonography and caliper in rats from groups I, II, and III. Therefore, the reduction obtained via ultrasonography was low, and the reduction detected using a caliper also tended to be low. Similarly, a high decrease in testicular volume observed via ultrasonography implies the detection of a substantial decrease in volume using a caliper.

\section{Conclusion}

There was significant agreement and a significant positive correlation in the percent reduction in the right testicular volume measured via ultrasonography and a caliper.

\section{References}

1. Gouletsou PG, Galatos AD, Leontides LS. Comparison between ultrasonographic and caliper measurements of testicular volume in the dog. Animal Reprod Sci. 2008;108:1-12. PMID: 17723281.

2. Nistal M, Paniagua R, Queizán A. Histologic lesions in undescended ectopic testes. Fertil Steril. 1985;43(3):455-62. PMID: 2858418.

3. Love CC, Garcia MC, Riera FR, Kenney RM. Evaluation of measures taken by ultrasonography and caliper to estimate testicular volume and predict daily sperm output in the stallion. J Reprod Fert. 1991;44:99-105. PMID: 1795307.

4. Koch GG, Landis JR. The measurement of observer agreement for categorical data. Biometrics. 1977;33(1):159-74. PMID: 843571.

5. Benge BN, Jordan GH. Prepubertal vasal injury: its effect on postpubertal vas deferens. J Urol. 1993;149:906-9. PMID: 8455272.

6. Chih-Chieh L, Huang WJS, Kuang-Kuo C. Measurement of testicular volume in smaller testes: how accurate is the conventional orchidometer? J Androl. 2009;30(6):685-9. PMID: 19578133.

7. Sakamoto H, Saito K, Oohta M, Inoue K, Ogawa Y, Yoshida H. Testicular volume measurement: comparison of ultrasonography, orchidometry and water displacement. Urology. 2007;69(1):152-7. PMID: 17270639.

8. Taskinen S, Taavitsainen M, Wikstrom S. Measurement of testicular volume: comparison of 3 different methods. J Urol. 1996;155:930-3. PMID: 8583610.

9. Diamond DA, Paltiel HJ, DiCanzio J, Zurakowski D, Bauer SB. Atala A, Ephraim PL, Grant R, Retik AB. Comparative assessment of pediatric testicular volume: orchidometer versus ultrasound. J Urol. 2000;164:1111-4. PMID: 10958754.

10. Fuse H, Takahara M, Ishii H, Sumiya H, Shimazaki J. Measurement of testicular volume by ultrasonography. Int J Androl. 1990;13:26772. PMID: 2201649. 
11. Shiraishi K, Takihara H, Kamiryo Y, Naito K. Usefulness and limitation of punched-out orchidometer in testicular volume measurement. Asian J Androl. 2005;7(1):77-80. PMID: 15685356.

12. Behre HM, Naschan D, Nieschlag E. Objective measurement of testicular volume by ultrasonography: evaluation of the technique and comparison with orchodometer estimates. Int $\mathrm{J}$ Androl. 1989;12:395-403. PMID: 2696729.

13. Sakamoto H, Yajima T, Nagata M, Okumura T, Suzuki K, Ogawa Y. Relationship between testicular size by ultrasonography and testicular function: measurement of testicular length, width an depth in patients with infertility. Int J Urol. 2008;15:529-33. PMID: 18430152.

14. Ariturk E, Ozates M. Measurement of testicular volume by ultrasonography. Turk J Pediatr. 1993;177-80. PMID: 8165750.

15. Stegani MM, Agulham MA, Ioshii SO. Testicular morphological damage in young rats after inguinotomy with vascular trauma. J Pediatr Surg. 2008;43(9):1705-10. PMID: 18779011.

16. Rosito NC, Koff WJ, Oliveira TLS, Cerski CT, Salle JLP. Volumetric and histological findings in intra-abdominal testes before and after division of spermatic vessels. J Urol. 2004;171:2430-3. PMID: 15126869 .

17. Montero AG, Vole C, Burda H, Malkemper EP, Holtze S, Morhart M, Saragusty J, Hildebrandt TB, Begall S. Non-Breeding Eusocial Mole-Rats Produce Viable Sperm-Spermiogran and Functional Testicular Morphology of Fukomys anselli. PLoS One. 2016;11(3):116. doi: 10.1371/journal.pone.0150112.

18. Aslan M, Kucukaslan I, Mulazimoglu S, Soyer T, Şenyücel M, Çakmak M, Scholbach J, Aslan S. Quantitative software analysis of ultrasonographic textures in experimental testicular torsion. Eur J Pediatr Surg. 2013;23(2):134-9. doi: 10.1055/s-0032-1324800.

19. Abdel-Razek AK, Ali A. Developmental changes of bull (Bos taurus) genitalia as evaluated by caliper and ultrasonography. Reprod Dom Anim. 2005;40:23-7. PMID: 15654997.

20. Gougoudi E, Zachariou Z, Kogia E, Zavitsanakis A. Testicular microlithiasis and Leydig cell proliferation in Wistar rats underwent Fowler-Stephens procedure. Pediatr Med Chir. 2012;34(4):192-7. PMID: 23173412.
21. Carlsen E, Anne-Grethe A, Buchreitz L, Jorgensen N, Magnus O, Matulevicuus V, Nermoen I, Petersen JH, Punab M, Suominen J, Zilaitiene B, Giwercman A. Inter-observer variation in the results of the clinical andrological examination including estimation of testicular size. Int J Androl. 2000;23:248-. PMID: 10886429.

22. Ceylan H, Karakok M, Guldur E, Cengiz B, Bagci C, Mir E. Temporary stretch of the testicular pedicle may damage the vas deferens and the testis. J Pediatr Surg. 2003 Oct;38(10):1530-3. PMID: 14577081.

23. Choi SE, Kook MC, Kim CJ, Lee SC, Park KW, Jung SE, Kim WK. Effects of compression/stretching of the spermatic cord and blunt dissection on testicular growth and fertility. J Pediatr Surg. 2009 Nov;44(11):2163-7. doi: 10.1016/j.jpedsurg.2009.03.025.

\section{Correspondence:}

Salomão Brêtas

Rua Eugenio Netto, 488/703

29055-270 Vitória - ES Brasil

Tel.: (55 27) 32277606 / 999826782

sbretas@gmail.com

Received: Mar 05, 2016

Review: May 08, 2016

Accepted: Jun 04, 2016

Conflict of interest: none

Financial source: none

${ }^{1}$ Research performed at Laboratory of Animal Experimentation, Research Center, Escola Superior de Ciências da Santa Casa de Misericórdia de Vitória (EMESCAM), Vitória-ES, Brazil. Part of PhD degree thesis, Postgraduate Program in Sciences Applied to Surgery and Ophthalmology, Universidade Federal de Minas Gerais (UFMG). Tutor: Edson Samesima Tatsuo. 